\title{
Qualidade da água como instrumento para a gestão hídrica da Bacia Hidrográfica Piranhas-Açu (Rio Grande do Norte, Brasil)
}

\section{Maria Alcilene Morais ${ }^{1}$, , Francisco Bruno Monte Gomes ${ }^{1}$, Luis César de Aquino Lemos Filho², George Satander Sá Freire $^{1}$, Gleydson de Freitas Silva ${ }^{2}$ e André Leone Facundo $^{3}$}

${ }^{1}$ Universidade Federal do Ceará. Centro de Ciências. Bloco 902. Campus do Pici. Fortaleza-CE, Brasil (CEP 60455-760).*E-mail: alcilenemorais@ymail.com.

${ }^{2}$ Universidade Federal Rural do Semi-Árido. Campus Mossoró. Rua Francisco Mota Bairro, 572. Pres. Costa e Silva, Mossoró-RN, Brasil (CEP 59625-900).

${ }^{3}$ Universidade Estadual do Ceará. Av. Dr. Silas Munguba, 1700. Itaperi. Fortaleza-CE, Brasil (CEP 60714-903).

Resumo. O monitoramento contínuo de qualidade das águas existentes nos recursos hídricos torna-se uma ferramenta poderosa para gerenciar antecipadamente problemas ambientais que venham a surgir quando os resultados apontam por não conformidades com a legislação nacional competente. Os gestores e tomadores de decisão ficarão munidos de ferramentas detalhadas que darão possibilidade de potencializar ações de preservação e conservação. Diante disso, a pesquisa teve como objetivo analisar a qualidade das águas no Rio Pataxó, do qual, está localizado na Bacia Hidrográfica Piranhas-Açu, Rio Grande do Norte. A metodologia consistiu em análises documentais, análises de campo, sendo demarcadas 10 estações amostrais ao longo do espelho d'água, culminando na coleta de amostras de água avaliando assim sua qualidade, para as variáveis físicas, químicas e microbiológicas, no período de abril/2018, julho/2018, fevereiro/2019 e julho/2019. Como resultados, notou-se que o Rio Pataxó atendeu em praticamente todos os parâmetros físicos, químicos e biológicos investigados, quando comparados com a Resolução CONAMA no 357/2005. Como o marco temporal abrangeu o período chuvoso e de estiagem na região, tal condição também foi observada, porém, conclui-se que apenas no período chuvoso é que houve uma pequena oscilação, mesmo assim atendeu ao exigido. Para estudos futuros sugere-se aumentar o número de variáveis e estender a avaliação para outras condicionantes, tais como, planos de monitoramento existentes na cidade, percepção dos usuários de água, dentre outros.

Palavras-chave: Gestão hídrica; Monitoramento; Qualidade da água.
Recebido

$20 / 06 / 2020$

Aceito

$08 / 12 / 2020$

Disponível on line

$10 / 12 / 2020$

Publicado

$31 / 12 / 2020$

Acesso aberto

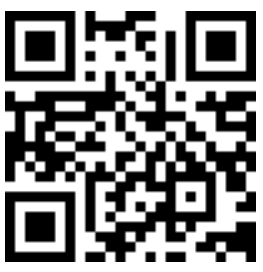

D 0000-0001-5632-0546 Maria Alcilene Morais

D 0000-0002-5703-627X

Francisco Bruno

Monte Gomes

ISSN 2359-1412/RBGAS-2020-0096/2020/7/17/33/1563

Rev. Bras. Gest. Amb. Sustent.

http://revista.ecogestaobrasil.net 
Abstract. Water quality as an instrument for water management in the Piranhas-Açu Hydrographic Basin (Rio Grande do Norte, Brazil). The continuous monitoring of water quality in water resources becomes a powerful tool to manage the environmental problems that may arise when the results show the non-conformities with the national legislation. The managers are supplied with detailed tools that will give the possibility to enhance preservation and conservation actions. Therefore, the research aimed to analyze the water quality in the Pataxó River, located in the Piranhas-Açu Hydrographic Basin. The methodology consisted of documentary analysis, field analysis, with ten sampling stations delimited along with the superficial water, culminating in the collection of water samples, thus evaluating their quality, for the physical-chemical and microbiological parameters, in the period of April/2018, July/2018, February/2019 and July/2019. As a result, was registered that the Pataxó River shows concordance in all investigated physical-chemical and biological parameters when compared with CONAMA Resolution 357/2005. In the time covered, the rainy and drought period in this basin, it is concluded that only in the rainy season was observed a small oscillation although the results attendees the resolutions. For future studies, suggested to increase the number of variables and extend the evaluation to other conditions, such as monitoring plans existing in the city, perception of water users, among others.

Keywords: Water management; Monitoring; Water quality.
(1) 0000-0001-8527-2686

Luis César de Aquino

Lemos Filho

(1) 0000-0001-8850-7225

George Satander Sá

Freire

D0000-0003-4217-9128

Gleydson de Freitas Silva

(D) 0000-0002-5869-6376

André Leone Facundo

\section{Introdução}

A água é o principal elemento responsável pela manutenção da vida no planeta terra, sendo fundamental ao desenvolvimento de diversos processos ecologicamente essenciais. Tomando como base os principais dados quantitativos, grande porcentagem das águas existentes na superfície terrestre é salgada com apenas uma pequena parcela considerada doce e acessível à consumação, ou seja, as medidas de preservação e conservação devem ser cada vez mais constantes.

De acordo com Jordão e Pessoa (2011), a disponibilidade qualitativa e quantitativa da água é o fator fundamental na fixação do homem e na formação de novas comunidades próximas às fontes dos recursos hídricos, assim sendo, estudos avaliativos que busquem conhecer tais aspectos é necessário para elevar qualidade ambiental local e regional.

Os estudos voltados à qualidade da água devem favorecer a compreensão dos possíveis impactos ambientais gerados por essa permanência antrópica para utilização dos corpos hídricos e assim funcionar como ferramenta de gestão constantes e eficientes (Batista e Cabral, 2017).

Em relação aos instrumentos normativos, o Brasil possui uma vasta listagem e cada um mais importante que o outro. A Política Nacional de Recursos Hídricos (PNRH) instituída através da Lei no 9.433/1997 (Brasil, 1997) está no centro do processo. Ela vem estabelecer um conjunto de princípios, objetivos, fundamentos e instrumentos que auxiliam no percurso sistemático metodológico em busca de atingir à preservação e conservação das águas. 
Quando pensado em padrões de referência para o monitoramento das águas, tal questão está determinada pela Resolução CONAMA no 357/2005 (Brasil, 2005), dispondo sobre a classificação dos corpos hídricos de acordo com seus usos preponderantes, estabelecendo diretrizes ambientais para o enquadramento das águas, bem como condições e padrões de lançamento de efluentes lançados aos corpos hídricos. A conformidade com os valores de referência é um bom indicativo da qualidade de um corpo hídrico, caso os resultados sejam contrários, acusa-se uma preocupação significativa aos gestores e tomadores de decisões (Anjinho et al., 2020). É importante destacar que cada Estado e município possuem suas próprias leis, artigos, portarias e resoluções, atendendo as realidades de cada região.

Tomando como base a região semiárida do Brasil é oportuno salientar que há justamente problemas em relação a quantidade dos recursos hídricos, principalmente devido ao período de distribuição irregular das precipitações, do qual, geralmente ocorrem em períodos concentrados, afetando o estoque e principalmente a qualidade em relação aos diversos usos mais comuns aos municípios desta área do país.

Diante disso, o objetivo principal deste estudo está em avaliar parâmetros físicos, químicos e biológicos de qualidade das águas em reservatório situado em região semiárida no Estado do Rio Grande do Norte.

\section{Materiais e métodos}

\section{Área de estudo}

A área de estudo está localizada na Bacia Hidrográfica Piranhas-Açu, na Região Centro-Norte no Estado do Rio Grande do Norte, no Município de Ipanguaçu, com foco central o Reservatório de Águas Superficiais Pataxó, que está situado entre as coordenadas geográficas $5^{\circ} 36^{\prime} 43,01^{\prime \prime}$ Sul e $36^{\circ} 50^{\prime} 51^{\prime \prime}$ Oeste.

0 referido corpo hídrico interliga-se ao Açude Público Federal de Armando Ribeiro Gonçalves através de um canal de perenização, do qual, fornece suprimento ao Perímetro Irrigado do Baixo-Açu. Sua capacidade máxima é de 15,02 milhões de $\mathrm{m}^{3}$ com favorecimento também aos usos múltiplos (abastecimento, irrigação, pesca). Na Figura 1, é possível observar a localização do mesmo, bem como, pontos de sua avaliação.

O Reservatório Pataxó foi construído em meados de 1951 e 1954 pelo Departamento Nacional de Obras Contra as Secas (DNOCS), sob a direção do Engenheiro Eurípedes Floresta de Oliveira, que na escavação do açude encontrou vestígios dos índios Pataxós (artesanatos, armas, dentre outros). Por consequência destes acontecimentos sobreveio à denominação do nome Pataxó ao manancial e à comunidade anteriormente chamada de Juazeiro (Souza e Guedes, 2020).

A região apresenta dois períodos bem definidos e distintos, o chuvoso e de estiagem. Segundo a EMPARN (2017), o período chuvoso está entre os meses de fevereiro a maio, com precipitações máximas em março e abril com médias de precipitações totais anuais de aproximadamente $630 \mathrm{~mm}$.

O clima da região, segundo a classificação climática de Köppen-Geiger, é do tipo BSwh' (Carmo Filho et al., 1990), predominantemente seco, com evapotranspiração potencial superior à precipitação total anual, ou seja, o que elevada os cuidados com sua manutenção. 


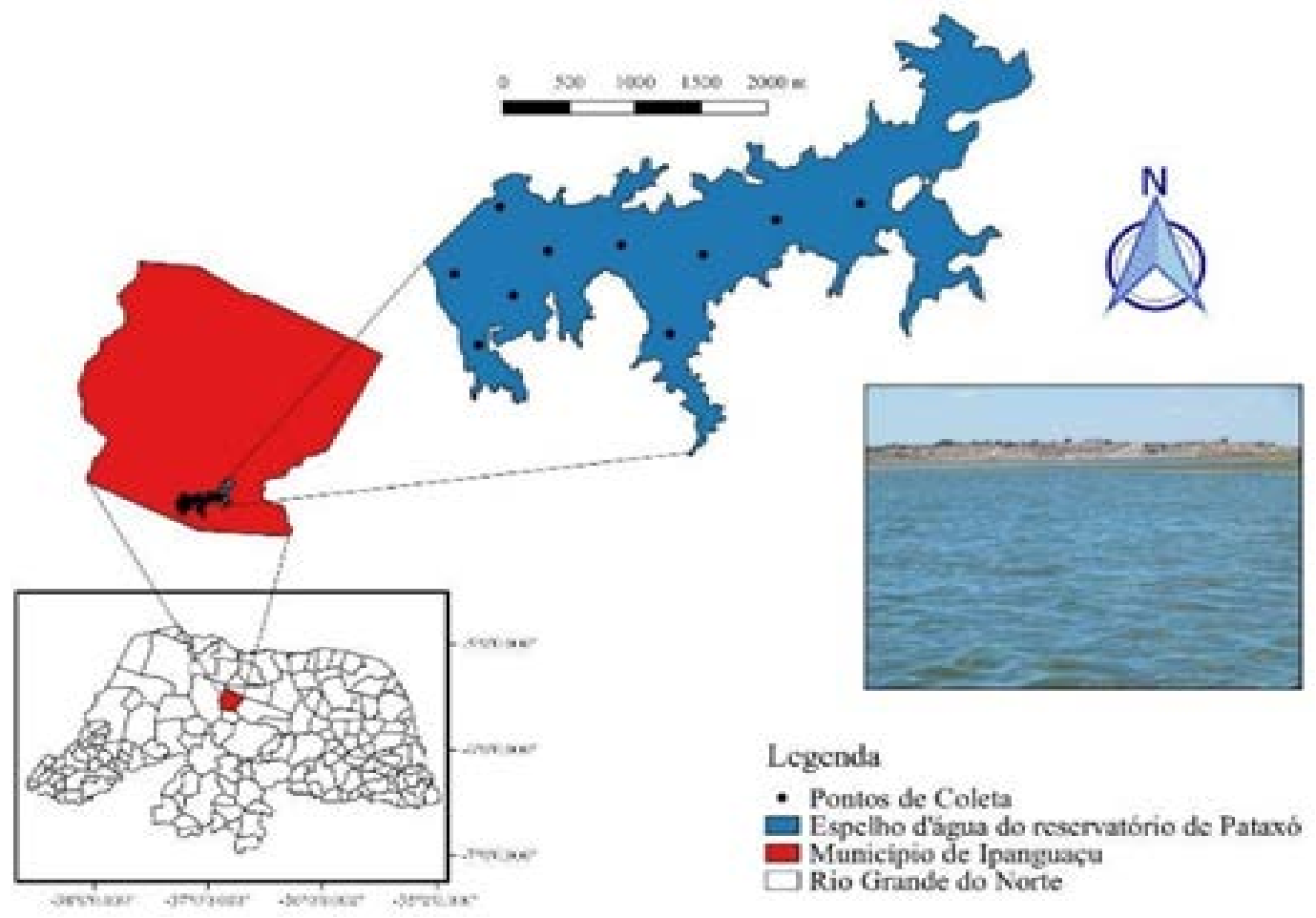

Figura 1. Localização do Reservatório de Pataxó.

\section{Procedimentos metodológicos}

As amostras de água foram coletadas durante quatro meses diferenciados (abril/2018, julho/2018, fevereiro/2019 e junho/2019), constituindo um espaço temporal que envolve a sazonalidade climática da região, isto é, compreendendo o período de estiagem, pré-estação chuvosa e a quadra invernosa.

Para uma amostragem analítica mais detalhada, foram estabelecidos dez pontos de coleta de água, com isso, as estações foram organizadas obedecendo a nomenclatura de P1 a P10. Os pontos de amostragem foram definidos de maneira a atender toda a área do reservatório.

O processamento das amostras ocorrera no Laboratório de Geologia Marinha e Aplicada, da Universidade Federal do Ceará (UFC), com foco nas variáveis físicas, químicas e para as microbiológicas houve o encaminhamento imediato ao Laboratório de Limnologia, da Universidade Federal Rural do Semiárido (UFERSA). Optou-se pelo modelo de pesquisa colaborativa por entender que a união de forças entre laboratórios distintos tende a reduzir custos e otimizar as análises (Chaym et al., 2018). As principais variáveis e métodos para o diagnóstico podem ser observados na Tabela 1.

É importante salientar que existe uma infinidade de variáveis que podem ser analisadas para que haja uma real concretude da situação de qualidade no ambiente. Contudo, devido as condicionantes econômicas há, de maneira geral, a escolha de um grupo central dos mesmos e como em outras experiências conseguem oferecer uma sólida discussão sobre sua qualidade. 
Tabela 1. Variáveis avaliadas na pesquisa e metodologias de determinação.

\begin{tabular}{|l|l|}
\hline Variáveis & \multicolumn{1}{c|}{ Métodos analíticos } \\
\hline $\mathrm{pH}$ & Eletrométrico (4500B) \\
\hline Temperatura $\left({ }^{\circ} \mathrm{C}\right)$ & Sonda \\
\hline Turbidez $(\mathrm{UNT})$ & $\begin{array}{l}\text { Turbidimêtrico com turbidímetro ThermoOrion, } \\
\text { modelo AD 2010 }\end{array}$ \\
\hline Nitrato $(\mathrm{mg} / \mathrm{L})$ & Coluna redutora de Cádmio (4500E) \\
\hline Fósforo Total $(\mathrm{mg} / \mathrm{L})$ & $\begin{array}{l}\text { Oxidação alcalina com persulfato de sódio, } \\
\text { seguida de método do ácido ascórbico }\end{array}$ \\
\hline Sólidos Totais $(\mathrm{mg} / \mathrm{L})$ & Fotometria de chama (3500B/3500B) \\
\hline Coliformes Totais $(\mathrm{NMP} / 100 \mathrm{~mL})$ & Tubos múltiplos (método analítico) \\
\hline Termotolerantes $(\mathrm{NMP} / 100 \mathrm{~mL})$ & Tubos múltiplos (método analítico) \\
\hline
\end{tabular}

Fonte: Eaton et al. (2017).

Os resultados foram avaliados através das diretrizes determinadas ao que constam na Resolução do CONAMA no 357/2005 (Brasil, 2005). Tal instrumento normativo estabelece o enquadramento dos corpos d'água em classes junto aos seus usos preponderantes. Com a classificação das águas doces como classe especial, classe I, classe II, classe III e classe IV.

Tabela 2. Variáveis e limites máximos estabelecidos pela Resolução CONAMA no 357/2005, complementada pela Resolução CONAMA nํ 430/2011.

\begin{tabular}{|l|c|}
\hline Variáveis & CLASSE II \\
\hline $\mathrm{pH}$ & $6,0-9,0$ \\
\hline Temperatura $\left({ }^{\circ} \mathrm{C}\right)$ & - \\
\hline Turbidez $(\mathrm{UNT})$ & $\leq 100$ \\
\hline Nitrato $(\mathrm{mg} / \mathrm{L})$ & $\leq 10,0$ \\
\hline Fósforo total $(\mathrm{mg} / \mathrm{L})$ & $\leq 0,1$ \\
\hline Sólidos Totais $(\mathrm{mg} / \mathrm{L})$ & $\leq 500$ \\
\hline Coliformes totais $(\mathrm{NMP} / 100 \mathrm{~mL})$ & $\leq 1000$ \\
\hline Coliformes termotolerantes $(\mathrm{NMP} / 100 \mathrm{~mL})$ & $\leq 1000$ \\
\hline
\end{tabular}

O Reservatório Pataxó está previamente classificado como classe II e para as variáveis analisadas serem os limites máximos permitidos, conforme apresentados na Tabela 2.

\section{Resultados}

Os rios são ecossistemas de grande importância ambiental e social, pois englobam diversos fins essenciais à vida humana, tais como abastecimento de água, geração de energia, insumo nos diferentes setores econômicos, fonte de pesca comercial, de lazer e atração turística. Porém, A poluição ocasionada pelos diversos usos dos recursos ambientais é uma das principais causas de detrimento da qualidade da água (Oliveira et al., 2010).

O objeto de estudo da presente pesquisa centraliza-se no Rio Pataxó que tem classificação, de acordo com a legislação em Classe II, suas águas podem ser destinadas 
para abastecimento e consumo humano (isso após tratamento convencional e proteção das comunidades aquáticas), para irrigação de hortaliças, plantas frutíferas e de parques, jardins, campos de esporte e lazer, com os quais o público possa vir a ter contato direto ou primário, para aquicultura e à atividade de pesca.

\section{Temperatura}

As variações de temperatura são parte do regime climático normal e corpos de água naturais apresentam variações sazonais e diurnas, bem como estratificação vertical. A temperatura superficial é influenciada por fatores tais como latitude, altitude, estação do ano, período do dia, taxa de fluxo e profundidade. A elevação da temperatura em um corpo d'água geralmente é provocada por despejos industriais (indústrias canavieiras, por exemplo) e usinas termoelétricas (CETESB, 2009).

Quando há uma variação negativa nas temperaturas, poderá ocorrer a solubilidade de gases dissolvidos na água, em particular o oxigênio, base para a decomposição aeróbia (Gomes, 2017).

Os resultados configuram que a temperatura na água manteve-se elevada, variando entre $27{ }^{\circ} \mathrm{C}$ e $31,6^{\circ} \mathrm{C}$ ao longo do período monitorado, apresentando no início, comportamento levemente crescente, aumentando a partir de abril/2018. Tal condicionamento pode estar relacionado à hora de coleta (entre $8 \mathrm{~h}$ e $12 \mathrm{~h}$ ).

Apesar da tendência de queda em época de chuvas, essas temperaturas não sofreram grandes alterações no período chuvoso de 2019. As variações podem ser conferidas na Figura 2-A. O instrumento normativo, tomado como referência de avaliação não menciona valores máximos ou mínimos. A temperatura é inversamente proporcional à concentração de oxigênio dissolvido, levando em conta o olhar físico (Nozaki et al., 2014). A Resolução CONAMA no 357/2005 não estabelece valores de referência para a temperatura.

\section{pH}

$\mathrm{O} \mathrm{pH}$ representa o equilíbrio entre íons $\mathrm{H}+$ e $\mathrm{OH}-$, ou seja, a intensidade das condições ácidas e alcalinas do meio. Sua escala antilogarítmica varia de 0 a 14, na qual valores inferiores a $7(\mathrm{pH}<7)$ indicam um meio ácido; valor igual a $7(\mathrm{pH}=7)$ meio neutro; e valores superiores a $7(\mathrm{pH}>7)$ meio alcalino. É um parâmetro de grande importância na rotina laboratorial em estudos de sistemas aquáticos, sobretudo em diversos processos e operações industriais (Rodrigues Neto, 2014).

Os resultados para esta variável (Figura 2-B) apontam que houve uma variação entre 6,8 e 8,2 com aumentos significativos principalmente no período chuvoso dos anos de 2018 e 2019. Nesse caso, os aumentos podem estar associados à maior mineralização da matéria orgânica, mesmo que parcialmente, podendo produzir elevadas concentrações de amônia, a qual, permanece livre devido ao baixo teor de OD no sistema e elevado pH.

Esteves (2011) informa que a presença de bicarbonatos e carbonatos na água pode desencadear aumento nos valores de pH. Esse fato foi comprovado por Pessoa (2002), em estudo realizado no Estuário do Rio Cocó, no Estado do Ceará.

Para rios como o Pataxó, classificado como Classe II, de acordo com a Resolução CONAMA no 357/2005, o pH pode variar entre 6 e 9. Dessa forma, teve suas análises em acordo conforme determinação acima citada.

Paula (2011) enfatiza que quando ocorre as variações de pH nas águas dos rios, poderá haver alterações na fisiologia de diversos organismos, indicam contaminação principalmente oriunda de efluentes industriais, além de contribuírem para a dissolução e precipitação de substâncias, muitas vezes tóxicas, como os metais pesados. 

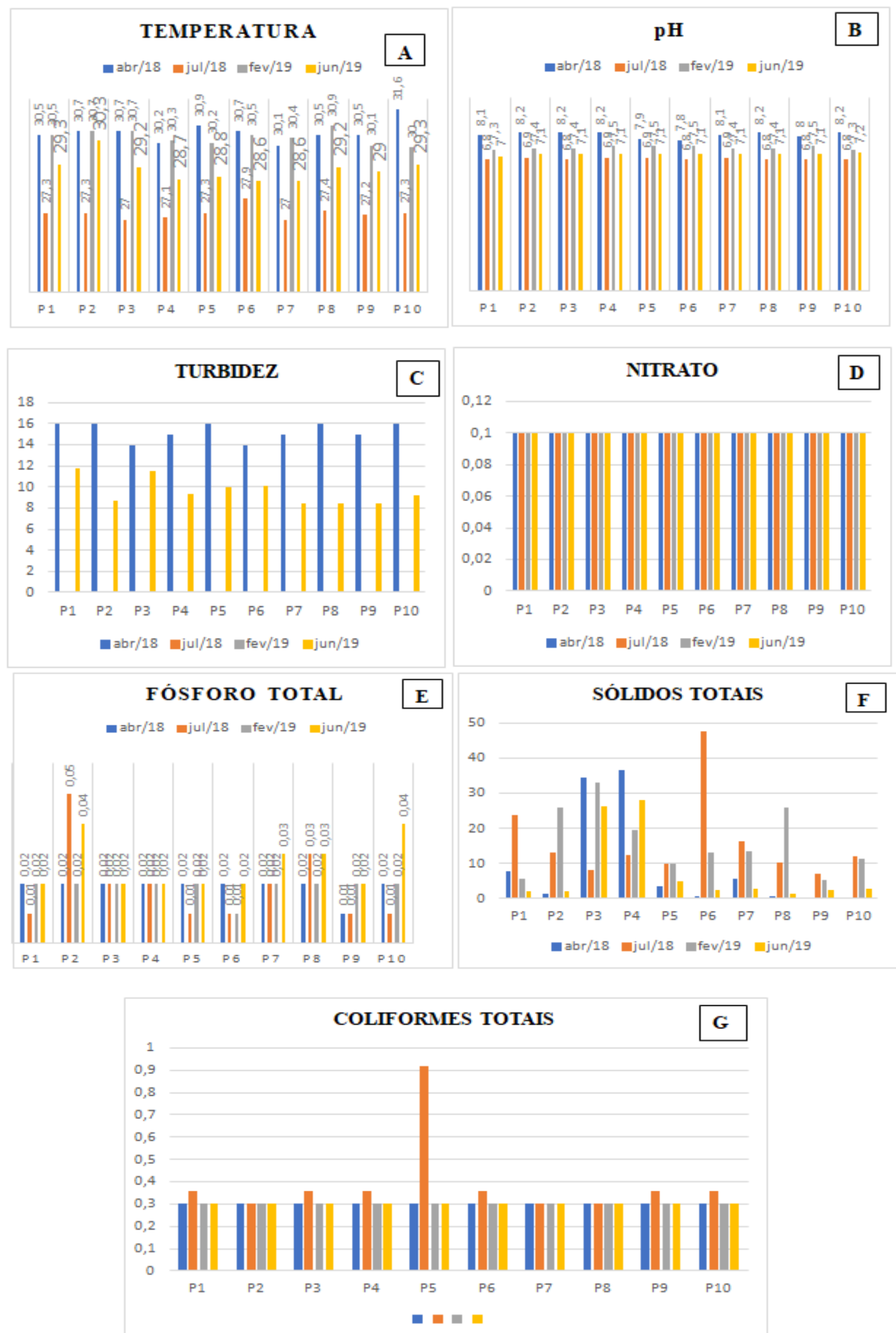

Figura 2. Variáveis monitoradas entre os anos de 2018 e 2019 para os meses compreendidos entre o período chuvoso e de estiagem. 


\section{Turbidez}

A variável turbidez possui a capacidade de verificar a carga de materiais sólidos através da medição de resistência da água à passagem de um feixe de luz. É provocada também pela presença de partículas flutuando, sendo uma variável de aspecto estético com caráter para aceitação ou rejeição.

Rodrigues Neto (2014) comenta que a determinação da turbidez tem se tornando um ótimo indicador para averiguar a presença de cistos e oocistos de protozoários (Giardia muris e Cryptosporidium parvum). Dessa forma, a remoção da turbidez vem se consolidando como uma das formas de avaliar sistemas de tratamento de água. Além disso, há uma relação direta entre a turbidez, com os sólidos suspensos e a cor aparente, sendo que esses valores tendem, como regra geral aumentar quando há ocorrência de precipitação pluviométrica.

Sobre a variação da turbidez nos pontos monitorados ao longo do Rio Pataxó, verificou-se que em cada ponto manteve-se em grandes oscilações, porém, permanecendo dentro do valor máximo permitido pela resolução para rios de classe 2 , qual seja 100 UNT da Resolução CONAMA no 357/2005, de acordo com os valores absolutos apresentados. Houve uma variação entre 8,7 e 16 UNT, com maiores concentrações nas estações P1, P2, P5, P8 e P10 (Figura 2-C).

\section{Nitrato}

O nitrogênio é considerado um dos elementos mais importantes no metabolismo dos ecossistemas aquáticos, sua concentração pode limitar a produção primária, aumentar a proliferação de microrganismos e apresentar potencial tóxico aos organismos aquáticos. Nos processos de degradação do nitrogênio são formados compostos como: amônia, nitrogênio amoniacal, nitrito, nitrato, entre outros. 0 nitrato está presente na maioria das águas superficiais e são oriundos de fontes humanas, animais e dos fertilizantes, por isso podem refletir a condição de saneamento da água (Brigante e Espíndola, 2003).

Durante todo o período da pesquisa, observou-se que houve uma predominância em $100 \%$ dos resultados para o quantitativo de nitrato presente nas águas do Rio Pataxó com resultados em $0,1 \mathrm{mg} / \mathrm{L}$ em todos os períodos (Figura 2-D).

Pontua-se que há totalidade em acordo com o predomínio da Resolução CONAMA no 357/2005 (menor ou igual a $10 \mathrm{mg} / \mathrm{L}$ ). Tal perfil revela que os registros favoreceram uma maior diluição desse composto nitrogenado pela coluna de água e pela maior oxidação favorecendo o processo de nitrificação.

\section{Fósforo total}

0 fósforo total em águas de rios pode ser de origem natural, proveniente de carreamento de solo, decomposição de matéria orgânica, chuva e ainda da dissolução de rochas como a apatita. Ou então pode ser proveniente de atividades humanas como uso de fertilizantes químicos de solo, agrotóxicos e efluentes de origem industrial e de esgotos na forma de detergentes altamente fosfatados e matéria fecal (Machado, 2006).

0 elemento aparece em águas naturais com proveniência fundamental através das descargas de esgotos sanitários. A matéria orgânica fecal e os detergentes em pó empregados em larga escala domesticamente constituem a principal fonte. Alguns efluentes industriais, como em indústrias de fertilizantes, pesticidas, químicas em geral, conservas alimentícias, abatedouros, frigoríficos e laticínios, apresentam fósforo em quantidades excessivas.

As concentrações de fósforo total no Rio Pataxó variaram de 0,02-0,01mg/L em abril de 2018 a 0,05-0,04-0,03 mg/L entre julho/2018, fevereiro/2019 e junho/2019, com distribuição específica em todos os pontos (Figura 2-E), portanto em conformidade com a legislação. 


\section{Sólidos totais}

O parâmetro de sólidos totais possui comportamento semelhante ao da turbidez, seu valor reflete a condição local, aumentando conforme o grau de poluição. 0 excesso dos sólidos altera as condições de luminosidade, interferindo no metabolismo de organismos autótrofos, por conta da dificuldade para a realização da fotossíntese, e nos organismos heterótrofos que dependem do oxigênio produzido durante a fotossíntese, afetando assim a comunidade aquática. Além de contribuir para processos de sedimentação e assoreamento, gerando o aumento do risco de enchentes em decorrência da diminuição da calha do rio segundo a ANA (2009) e CETESB (2012).

Os resultados no Rio Pataxó apontam que os maiores valores foram encontrados no P3 com ordem máxima de 34,6 mg/L (período chuvoso/2018), com seu menor valor de 01. mg/L no P9 também para o ano acima citado. Os demais pontos houve oscilações (Figura 2-F), contudo, em nenhum cenário houve o desacordo com a Resolução CONAMA no $357 / 2005$.

\section{Coliformes totais e termotolerantes}

Os coliformes totais (bactérias do grupo coliforme) - bacilos gram-negativos, aeróbios ou anaeróbios facultativos, não formadores de esporos, oxidase-negativos, capazes de desenvolver na presença de sais biliares ou agentes tensoativos que fermentam a lactose com produção de ácido, gás e aldeído a $35,0{ }^{\circ} \mathrm{C} \pm 0,5^{\circ} \mathrm{C}$ em $24-48 \mathrm{~h}$, e que podem apresentar atividade da enzima $ß$ - galactosidase. A maioria das bactérias do grupo coliforme pertence aos gêneros Escherichia, Citrobacter, Klebsiella e Enterobacter, embora vários outros gêneros e espécies pertençam ao grupo (Brasil, 2013).

A razão da escolha desse grupo de bactérias como indicador de contaminação da água deve-se aos seguintes fatores: estão presentes nas fezes de animais de sangue quente, inclusive os seres humanos, sua presença na água possui uma relação direta com o grau de contaminação fecal, são facilmente detectáveis e quantificáveis por técnicas simples e economicamente viáveis, em qualquer tipo de água.

As estações amostrais P5 (0,92 NMP/100 mL), P1, P3, P4, P6, P9, P10 $(0,36 \mathrm{NMP} / 100 \mathrm{~mL})$ em julho/2019 foram as que classificaram os valores mais significativos, tendo os demais meses, permanecidos constantes na ordem de 0,3 NMP/100 mL, ou seja, com total conformidade com a legislação (Figura 2-G).

Os coliformes termotolerantes são definidos como subgrupos das bactérias do grupo coliforme que fermentam a lactose a $44,5{ }^{\circ} \mathrm{C} \pm 0,2{ }^{\circ} \mathrm{C}$ em $24 \mathrm{~h}$, possui como fundamental representante da Escherichia coli (E. coli), de origem exclusivamente fecal. Em laboratório, tomando como processo posterior o da análise dos coliformes totais, todos os resultados para o período total de avaliação foram todos negativos.

Tais obtenções de resultados são bastante animadoras, tendo em vista que as análises para essa variável indicam não há o desenvolvimento de nenhum processo de contaminação ambiental externa na área totalitária do recurso hídrico e região de entorno. Com isso, pode-se dizer que organismos aquáticos estejam preservados, bem como, a manutenção equilibrada dos usos múltiplos.

\section{Conclusão}

A pesquisa realizada com o objetivo de conhecer a realidade da qualidade de água, mediante a perspectiva apresentada sobre variáveis determinadas em laboratórios específicos para a área do Rio Pataxó, concluiu que a temperatura, $\mathrm{pH}$, turbidez, nitrato, fósforo total, sólidos totais e coliformes totais alcançaram conformidades necessárias com os limites máximos exigidos por resolução do CONAMA específica, que tem o intuito de classificar as águas em corpo de água de acordo com usos preponderantes demarcados. Como propostas futuras entende-se a necessidade de aumentar a listagem de variáveis a 
serem investigas, bem como, relacionar com maiores evidências os usos múltiplos do referido recurso hídrico e dialogando com se está ou não havendo influência nessa qualidade. 0 estudo tornou-se de grande valia aos gestores de águas quando pensar na visão de determinação de políticas públicas de conservação ambiental.

\section{Agradecimentos}

Os autores agradecem à Coordenação de Aperfeiçoamento de Pessoal de Nível Superior (CAPES) pelo apoio e financiamento da pesquisa.

\section{Conflito de interesses}

Os autores declaram não haver conflito de interesses.

\section{Referências}

ANA - Agência Nacional das Águas. Índice de qualidades das águas. 2009. Disponível em: <http://pnqa.ana.gov.br/indicadores-indice-aguas.aspx>. Acesso: 04 maio 2020.

Anjinho, P. S.; Neves, G. L.; Barbosa, M. A. G. A.; Mauad, F. F. Análise da qualidade das águas e do estado trófico de cursos hídricos afluentes ao Reservatório do Lobo, Itirapina, São Paulo, Brasil. Revista Brasileira de Geografia Física, v. 13, p. 364-376, 2020. https://doi.org/10.26848/rbgf.v13.1.p364-376

Eaton, A. D.; Clesceri, L. S.; Greenberg, A. E. (Eds.). Standard methods for the examination of water and wastewater. 23. ed. Washington: American Public Health Association, American Water Works Association, Water Environmental Federation, 2017.

Batista, D. F. B.; Cabral, J. B. P. C. Modelos matemáticos para avaliação do índice de qualidade de água. Acta Geográfica, v. 11, n. 25, p. 111-136, 2017.

Brasil. Fundação Nacional de Saúde. Manual prático de análise de água. 4. ed. Brasília: Fundação Nacional de Saúde, 2013.

Brasil. Lei no 9.433, de 8 de janeiro de 1997. Institui a Política Nacional de Recursos Hídricos, cria o Sistema Nacional de Gerenciamento de Recursos Hídricos, regulamenta o inciso XIX do art. 21 da Constituição Federal, e altera o art. 1ำ da Lei ํo 8.001, de 13 de março de 1990, que modificou a Lei no 7.990, de 28 de dezembro de 1989. Disponível em: <http://www.planalto.gov.br/ccivil_03/leis/19433.htm>. Acesso: 04 maio 2020.

Brasil. Resolução CONAMA no 357, de 17 de março de 2005. Dispõe sobre a classificação dos corpos de água e diretrizes ambientais para o seu enquadramento, bem como estabelece as condições e padrões de lançamento de efluentes, e dá outras providências. Disponível em: <http://www2.mma.gov.br/port/conama/legiabre.cfm? codlegi=459>. Acesso: 04 maio 2020.

Brasil. Resolução CONAMA no 430, de 13 de maio de 2011. Dispõe sobre condições e padrões de lançamento de efluentes, complementa e altera a Resolução no 357, de 17 de março de 2005, do Conselho Nacional do Meio Ambiente - CONAMA. Disponível em: <http://www2.mma.gov.br/port/conama/legiabre.cfm?codlegi=646>. Acesso: 04 maio 2020 .

Brigante, J.; Espíndola, E. L. G. Limnologia fluvial: um estudo no Rio Mogi-Guaçu. São Carlos: RiMa, 2003.

Carmo Filho, F.; Espinola S, J.; Maia Neto, J. M. Dados meteorológicos de Mossoró. Mossoró: ESAM, 1990. (Coleção Mossoroenses, série C, v. 639). 
CETESB - Companhia de Tecnologia de Saneamento Ambiental de São Paulo. Qualidade das águas interiores no Estado de São Paulo. 2009. Disponível: em: <http://cetesb.sp.gov.br/aguas/wpcontent/uploads/sites/32/2013/11/variaveis.pdf>.

Acesso em: 19 maio 2020.

CETESB - Companhia de Tecnologia de Saneamento Ambiental de São Paulo. Relatório da qualidade das águas interiores do Estado de São Paulo. 2012. Disponível em: <http://www.cetesb.sp.gov.br/agua/aguas-superficiais/35-publicacoes-/-relatorios>. Acesso em: 20 abr. 2020.

Chaym, C. D.; Barroso, W. D. M. A.; Melo, J. M. G. N.; Benayon, P. A.; Moreira, A. F. Produção de conhecimento em ciência, tecnologia \& inovação: uma avaliação dos doutores formados pela Rede Nordeste de Biotecnologia. Revista Gestão em Análise, v. 7, n. 2, 2018. https://doi.org/10.12662/2359-618xregea.v7i2.p133-150.2018

EMPARN - Empresa de Pesquisa Agropecuária do Rio Grande do Norte. Gerência de Meteorologia. Climatologia Rio Grande do Norte. 2017. Disponível em: <http://189.124.201.150/climaRN/medias_historicas_municipios_RN.htm>. Acesso em: 15 maio 2020.

Esteves, F. Fundamentos da limnologia. Rio de Janeiro: Interciência, FINEP, 2011.

Gomes, F. B. M. Análise da qualidade ambiental do Rio Acaraú no espaço intraurbano da Cidade de Sobral-CE: efeitos, consequências e desafios. Sobral: Universidade Estadual Vale do Acaraú, 2017 (Dissertação de mestrado).

Jordão, E. P.; Pessoa, C. A. Tratamento de esgotos domésticos. 6. ed. Rio de Janeiro: ABES, 2011.

Machado, W. C. P. Indicadores da qualidade da água na Bacia Hidrográfica do Rio Pato Branco. Curitiba: Universidade Federal do Paraná, 2006.

Oliveira, C. N.; Campos, V. P.; Medeiros, Y. D. P. Avaliação e identificação de parâmetros importantes para a qualidade de corpos d'água no semiárido baiano. Estudo de caso: Bacia Hidrográfica do Rio Salitre. Química Nova, v. 33, n. 5, p. 1059-1066, 2010. https://doi.org/10.1590/S0100-40422010000500010

Paula, L. M. Avaliação da qualidade da água e autodepuração do Rio Jordão, Araguari (MG). Uberlândia: Universidade Federal de Uberlândia, 2011. (Dissertação de mestrado).

Pessoa, E. V. Estudo do standing-crop da água do Estuário do Rio Cocó (Ceará Brasil), como indicador das modificações físico-químicas do meio. Fortaleza: Universidade Federal do Ceará, 2002 (Dissertação de mestrado).

Rodrigues Neto, M. P. Estudo da qualidade de águas de poços no Iguape-CE. Fortaleza: Universidade Federal do Ceará, 2014. (Dissertação de mestrado).

Souza, Y. K. L.; Guedes, J. A. Percepção ambiental sobre o Reservatório de Pataxó (Ipanguaçu/RN). Revista Presença Geográfica, v. 7, n. 1, 2020. https://doi.org/ 10.36026/rpgeo.v7i1.4989

Informação da Licença: Este é um artigo Open Access distribuído sob os termos da Licença Creative Commons Attribution, que permite uso irrestrito, distribuição e reprodução em qualquer meio, desde que a obra original seja devidamente citada. 